\title{
Ecological Economic Modeling of Coral Reefs: Evaluating Tourist Overuse at Hanauma Bay and Algae Blooms at the Kinhei Coast, Hawai ${ }^{i}{ }^{1}$
}

\author{
Pieter 7. H. van Beukering ${ }^{2}$ and Herman S. 7. Cesar ${ }^{2,3}$
}

\begin{abstract}
In this paper we present the first ecological economic model of coral reefs in Hawai' $i$. This model contains the main elements required to assess the full picture of coral reef management and thereby enables scientists and managers to evaluate ecological and economic impacts effectively. The model is applied to two case studies, tourist overuse in Hanauma Bay, O'ahu, and algae blooms along the Kinei coast, Maui. The Hanauma study showed that visitors are willing to pay much more for their experience (around $\$ 10$ ) than they are currently doing and that the net benefits of the education program (around \$100 million) greatly exceed the cost of the program (around \$23 million) over time. The Kinei coast study concluded that the algae problem causes large losses of real estate value and hotel business and that mitigation could result in benefits of $\$ 30$ million over time. This would justify major investments in lowering nutrient discharges in the coastal zone.
\end{abstract}

All over THE world, anthropogenic disturbances have been linked to the vast majority of decreases in coral cover (Birkeland 1995). In Hawai'i, one of the largest threats to coral reefs is human expansion and economic development (Clark and Gulko 1999, Gulko et al. 2001). Whether it is direct sedimentation onto the reef, or an increase in the turbidity of the water due to eutrophication, or increases in the amounts of nutrients that en-

${ }^{1}$ This publication is a result of research funded by the National Oceanic and Atmospheric Administration (NOAA), Coastal Ocean Program, under awards NA870A0381, NA960P0187, NA060A0388, and NA160A1449 to the University of Hawai'i for the Hawai'i Coral Reef Initiative Research Program. This paper is a summary of components of Cesar et al. (2002). Manuscript accepted 27 May 2003.

2 Institute for Environmental Studies, Vrije Universiteit, Boelelaan 1087, $1081 \mathrm{HV}$, Amsterdam, The Netherlands (phone: +31-20-4449555; fax: +31-20-4449553; E-mail: beukering@ivm.vu.nl).

${ }^{3}$ Cesar Environmental Economics Consulting, Kastanjelaan 9, 6828 GH, Arnhem, The Netherlands (phone: ++31-26-4452175; fax: $++31-26-7502451$; E-mail: herman.cesar@ivm.vu.nl).

Pacific Science (2004), vol. 58, no. 2:243-260

(C) 2004 by University of Hawai'i Press hance the growth of other reef organisms, all these impact on coral health.

The interaction between ecological and economic processes is complex. Yet, it is often this interaction between the two dimensions that is crucial to our understanding of why coral reefs are degrading and how such degradation can be prevented. Therefore, there is an urgent need for a more systematic approach to the integration of ecological and economic processes.

To effectively evaluate the complex interface between reef-related ecological and economic processes, simulation modeling can play a useful role. Modeling techniques allow for systematically structuring the multifaceted web of ecological and economic relationships while providing quantification of the examined scenarios. The objective of the study is threefold: (1) to develop an ecological economic model of the coral reefs of Hawai' $i$; (2) to apply the model to specific selected case study areas; and (3) to determine the economic costs of reef degradation and to compare costs and benefits of various management options that aim to reverse the trends in these case study areas.

To demonstrate the developed model, two case studies were selected within the region of the main Hawaiian Islands (Figure 1): Ha- 


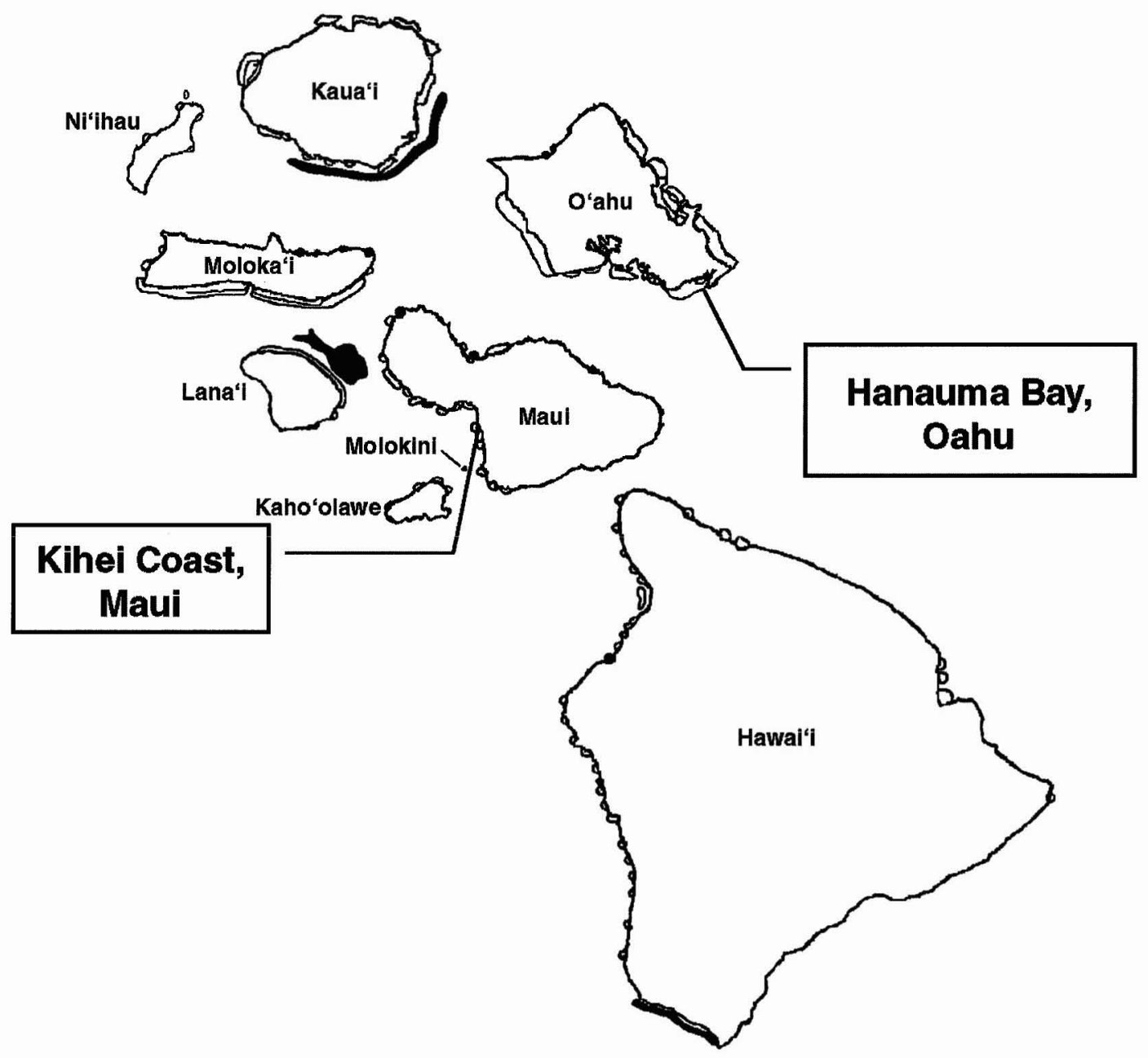

Figure 1. The main Hawaiian Islands and the selected case studies.

nauma Bay ( $\mathrm{O}^{\prime} \mathrm{ahu}$ ), addressing tourist overuse, and Kîhei (Maui), addressing excessive nutrients and algae blooms.

\section{MATERIALS AND METHODS}

\section{The Model}

A simplified dynamic simulation model has been developed to deal with the environmental and economic complexities that surround coral reefs in Hawai'i. This integrated model, referred to as SCREEM (Simple
Coral Reef Ecological Economic Model), links ecology and economy in a dynamic manner. SCREEM incorporates the relevant ecological economic relations by following pathways linking the type of coral reef ecosystem and its uses and location with the physical goods and services provided by this reef type and the economic value of these values. The model was developed with the software package VENSIM (2000). A conceptual version of an ecological economic model for coral reef decision making was presented by Gustavson et al. (2000). 


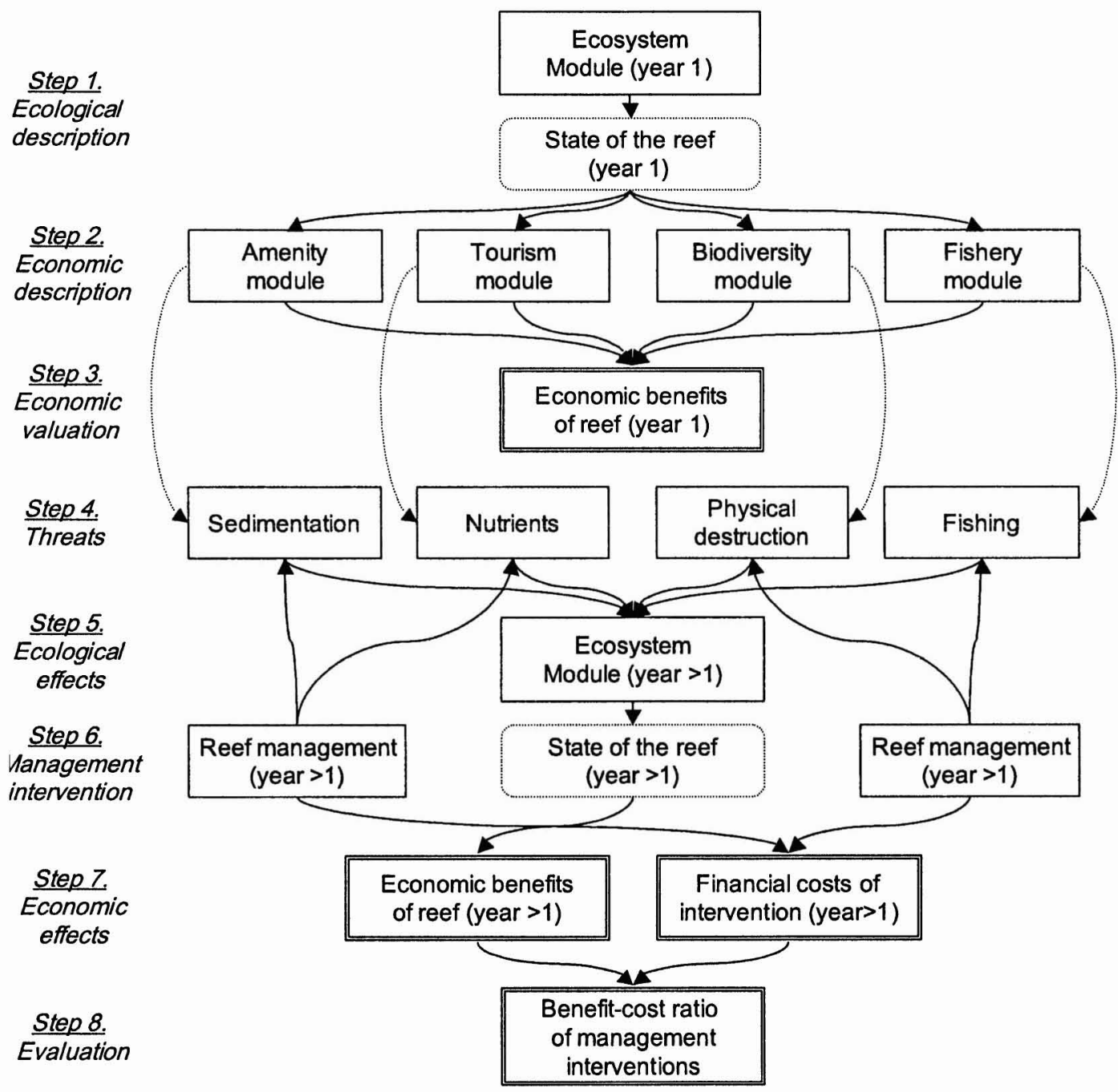

Figure 2. General framework of the dynamic simulation model.

Figure 2 highlights the key features of this model and the interactions between different ecological and economic components. It also shows the threats and their impact on ecological factors, as well as the necessary interventions required to mitigate these threats. Finally, the associated costs and benefits of the interventions are displayed. The model uses a 50-yr period (2000-2050); this allows enough time for the main ecological outcomes to come into effect while being short enough to allow for predictions about future developments. For a general discussion on time horizons in environmental economics, see Pearce and Turner (1990).

Step 1 combines the five main ecological indicators (coral cover, coral biodiversity, fish stock, fish biodiversity, and macroalgae cover) into one composite "state of the reef" indicator. Step 2 of the model describes the various reef ecosystem functions, which are translated into reef-associated goods and ser- 
vices to Hawai'i society. The goods and services here are fisheries, tourism, amenities, and biodiversity, although the model can be adjusted easily to incorporate additional functions and goods and services (Moberg and Folke 1999).

Each of these goods and services has associated economic benefits. The value of the sum of compatible uses of these goods and services forms the total economic value of coral reef ecosystems (e.g., Spurgeon 1992, Barton 1994, Costanza et al. 1997). The procedure of calculating the total economic value of different coral reefs in Hawai' $i$ is explained in detail in Cesar and Van Beukering (2004, this volume). In this article we limit ourselves to explaining the main features of SCREEM and to presenting the case study results. In the following, the model is presented in separate modules that are interrelated. These modules include ecology, tourism, amenities, and biodiversity. Because the two case studies lack substantial benefits and dynamics of fisheries, the fishery module is not specifically addressed in this article (see Friedlander and Parrish [1998] and the literature quoted there).

ECOLOGICAL MODUle. The complexity of the ecology of coral reefs makes it difficult to model these processes in a realistic manner. To simulate the numerous interdependencies and the multiple threats to coral reefs requires a huge modeling effort with enormous data needs. Even then, it leaves us with large scientific uncertainties. On the other hand, ignoring the ecological processes in the analysis is also undesirable. Therefore, we have developed an ecological module in SCREEM on the basis of existing knowledge and literature. The basic structure of this model is shown in Figure 3.

SCREEM is designed to simulate various different types of threats to the Hawaiian coral reefs. In the two case studies described here we particularly focus on two threats (Grigg and Dollar 1990). In the Hanauma Bay case study, we look specifically at the threat of tourism overuse. (Uncontrolled tourist development can lead to physical destruction of coral through trampling, contact with divers, and anchor damage.) The case study in Kinhei focuses on the combination of excess nutrients, runoff, and coastal hardening, thought to be some of the main causes of the algae blooms in North Kinei. (Insufficient sewage treatment can lead to excess nutrients that stimulate algae growth, which can overgrow the corals. This problem is particularly acute close to estuaries of rivers and urban centers [Rogers 1990].) To understand the impact of the individual threats a literature review was conducted (see Cesar et al. [2002] for more details). From this review relationships were estimated between the threats and the different ecological indicators of the coral reef.

SCREEM addresses five ecological indicators that represent the most important environmental characteristics of a coral reef. These are coral cover, coral biodiversity, fish stock, fish biodiversity, and macroalgae cover. These variables are exogenously determined for the first year of the analysis and develop endogenously over time. To present these ecological indicators in a workable manner, and to connect them to the economic modules, a composite indicator is constructed: "the state of the reef" indicator.

The following sequential stages take place in the ecological module. First, the individual ecological indicator scores are normalized into a score between 0 and 1 . For example, in a site where the maximum coral cover is $60 \%$ and the minimum is $0 \%$, these levels are defined as 1 and 0 , respectively. A coral cover of $30 \%$ is then interpolated linearly with a score of 0.5 . The relationship between the normalized score and the indicator is called the value function. Although this function can have different shapes, in our model this function is assumed to be linear. Second, the normalized individual scores are aggregated by attaching weights to the indicators that represent the relative ecological importance of the indicator as compared with the other indicators. In Hawai' $i$ the following weights have been applied: coral cover (30\%), coral biodiversity (20\%), fish stock (20\%), fish biodiversity $(15 \%)$, and macroalgae cover (15\%). These weights are based on expert judgments. Finally, the behavior over time of the "state of the reef" indicator, which by definition 


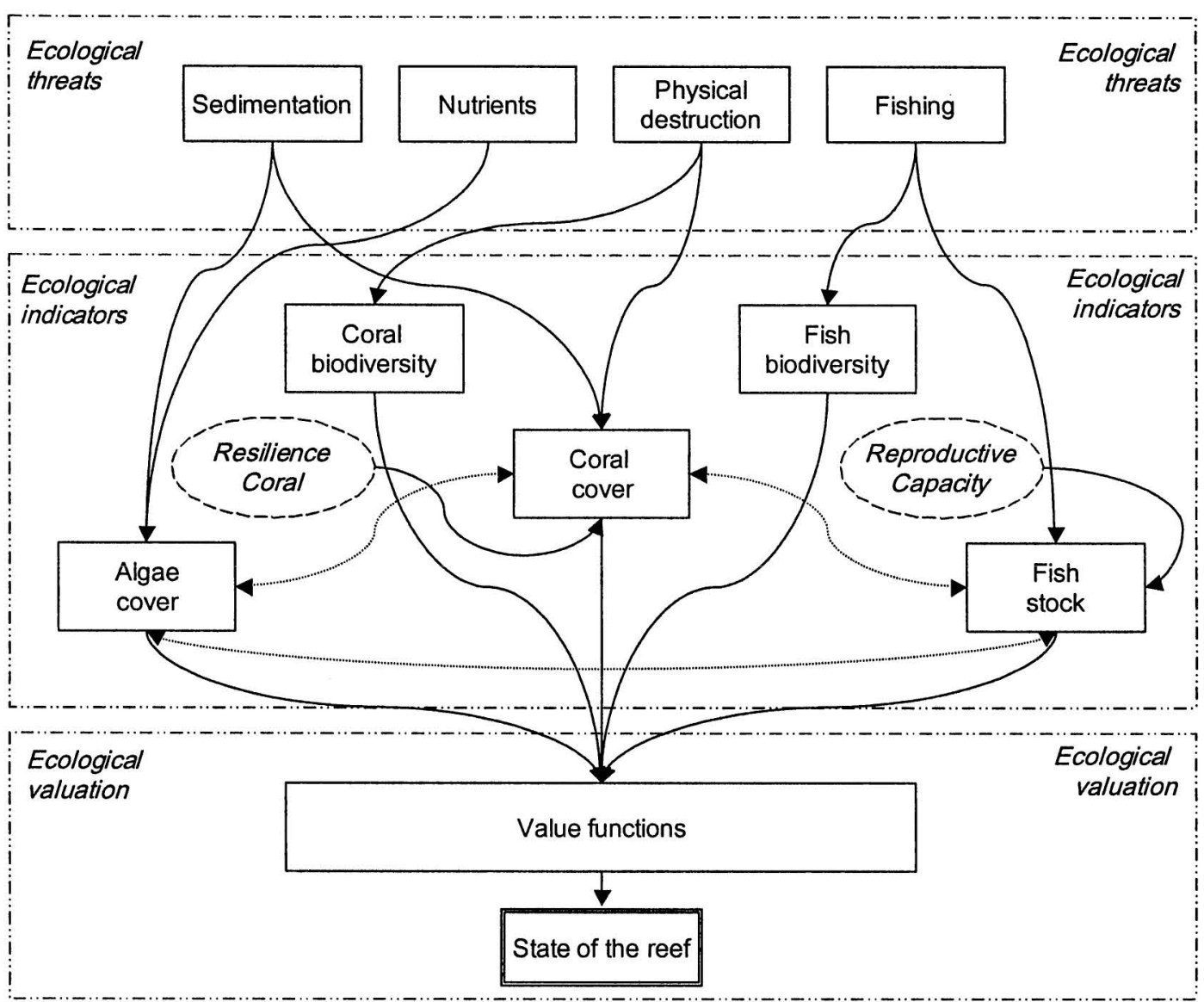

Figure 3. Ecological module.

moves between a score of 0 and 1 , is determined. The three stages fall within the ecological module. The modules discussed next address processes that fall within the boundaries of the economy.

TOURISM MODUle. Some 200,000 divers and more than 3 million snorkelers enjoy the Hawaiian reefs every year. They pay a substantial amount in direct and indirect expenditure to admire the unique marine life. Thereby they support a large aquatic tourist industry. In 2002, more than 100 dive and snorkeling operators were registered in $\mathrm{Ha}-$ wai $i$, earning between $\$ 50$ and 60 million per annum. But the recreational expenditures related to coral reefs extend much further than direct dive- and snorkel-related revenues. Bus and taxi drivers bring tourists to popular destinations such as Hanauma Bay, and hotels lodge these same tourists and restaurants feed them after a long day in the water. Therefore, calculating the recreational benefits involves much more than simply adding up the value added of the dive and snorkel industry. In fact, it involves calculating producer surplus for both direct and indirect expenditure as well as consumer surplus. This is described in detail in this issue in Cesar and Van Beukering (2004).

To determine the dynamics of the recreational benefits, prices and quantities for 2001 were fed into the model. Figure 4 shows the overall structure of the tourism module. An important assumption in the model is the re- 


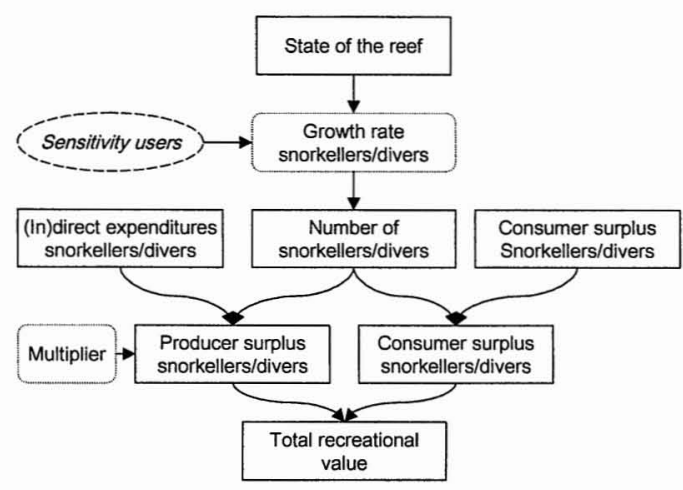

Figure 4. Tourism module.

lationship between the growth rate and the "state of the reef." Both the dive industry survey and the diver and snorkel survey indicated the dependency of marine activities on the quality of coral reef ecosystems. If the quality of the reef worsens further over time, fewer tourists will decide to go snorkeling or diving. In fact, the growth rate may even become negative at a certain given quality level of the coral reefs. The last step in the tourism module is the summation of the consumer and producer surplus for both the diving and snorkeling activities into the total recreational value. amenity module. Houses, hotels, and condominiums in the vicinity of a healthy marine system are generally more valuable than comparable properties elsewhere. This surplus value of houses and hotel rooms in the vicinity of healthy marine systems has been measured through a survey that we carried out. Combining this with the number of the residential houses, condominiums, and hotel rooms leads to a positive amenity value attributable to a healthy coral reef. On the basis of the expert judgment of real estate agents we assumed that $1.5 \%$ of the sale price of the properties is attributable to the coral reefs. This is shown by the outer part of Figure 5.

In the case of a negatively impacted coral reef ecosystem, such as seen at North Kinei in Maui, this positive value will be much lower. The macroalgae problem on the Kihei coast is believed to cause a negative impact on property values of the affected condominiums as well as the rental prices and vacancy rates in transient accommodations. Therefore, in addition to the positive value attributed to the beneficial aspects of a coral reef, negative impacts are occurring as a result of the corallinked algae problem. This additional negative impact on the amenity value is indicated in Figure 5 by the shaded segment.

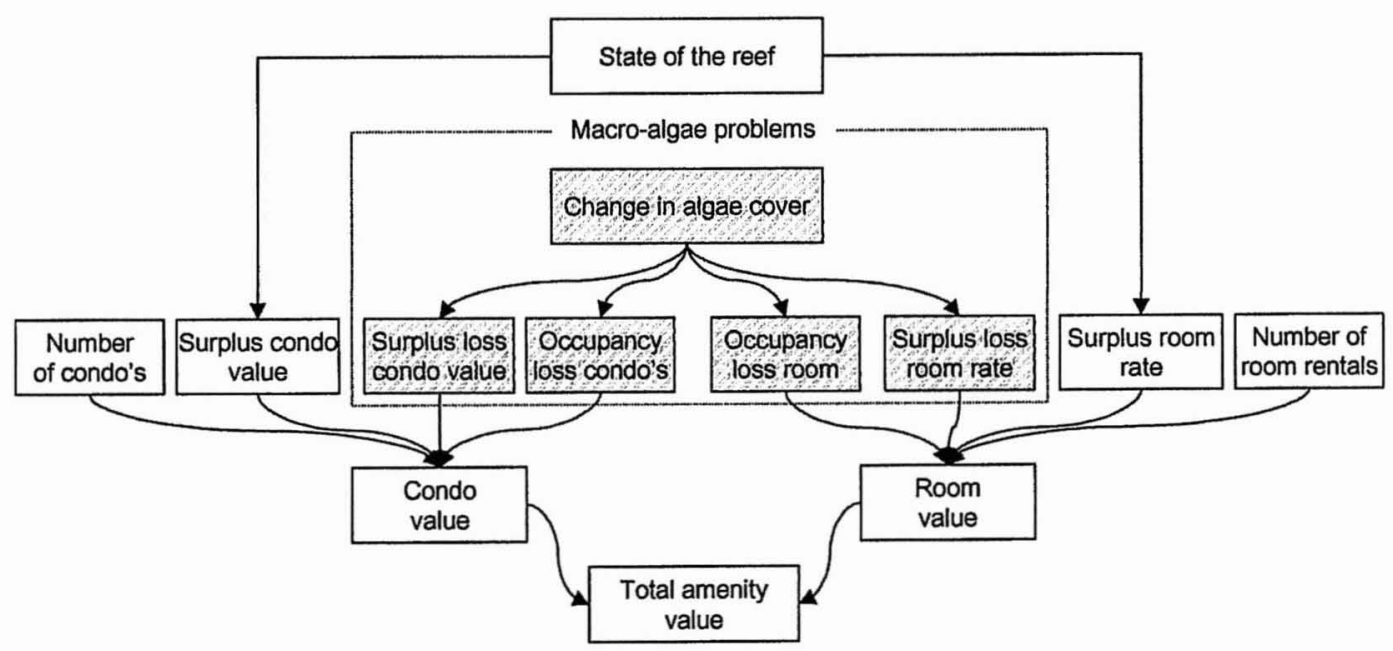

Figure 5. Amenity module. 


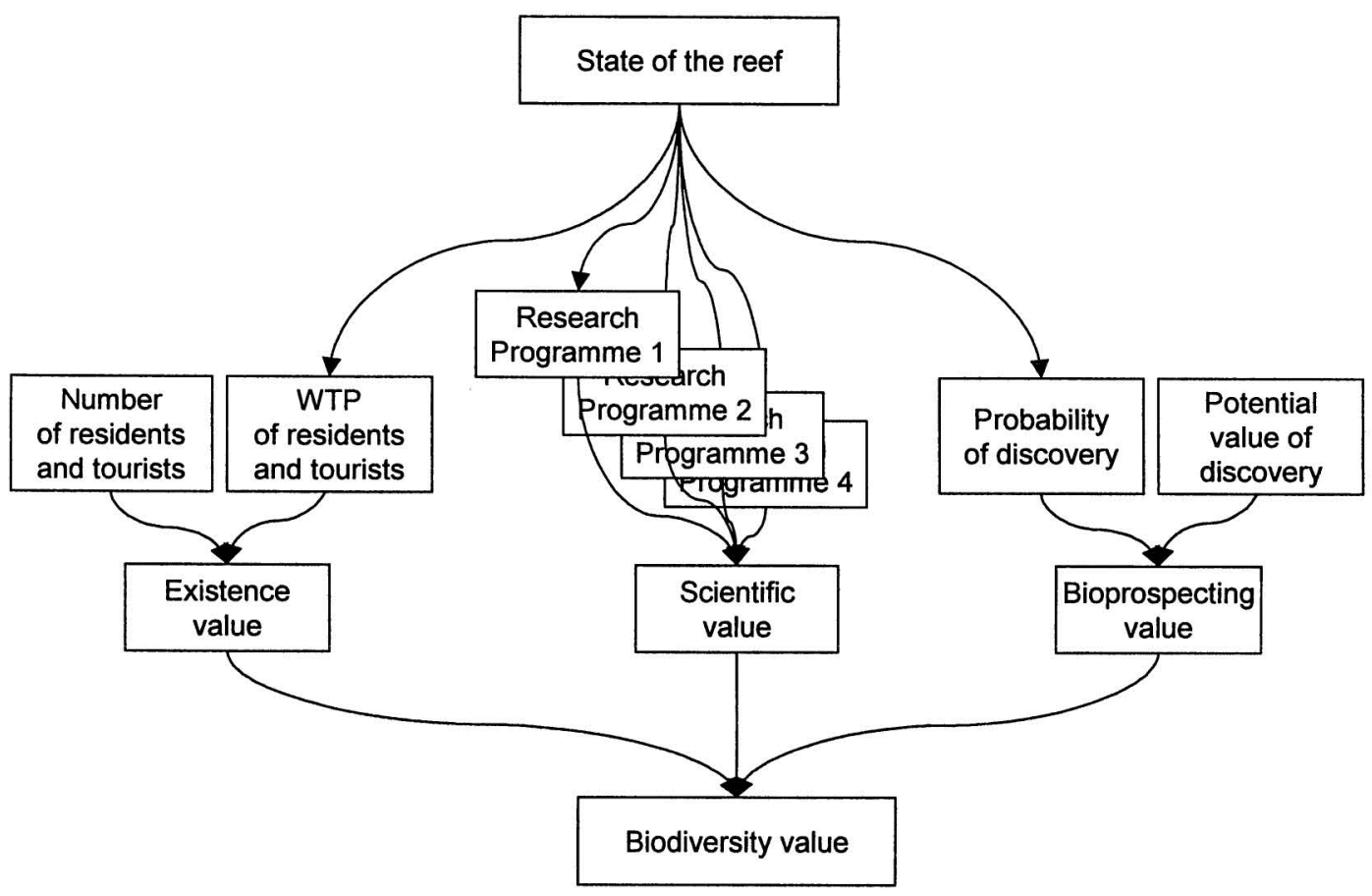

Figure 6. Biodiversity module.

BIODIVERSITY MODULE. The existence of a great number of endemic species makes the Hawaiian coral reefs a unique natural resource. This reef biodiversity aspect generates economic benefits. Figure 6 shows the main components of the so-called biodiversity module. These include the scientific or research value, the nonuse value, and the bioprospecting value.

The bioprospecting value refers to the revenues pharmaceutical companies may be able to retrieve from the diverse genetic pool contained by the Hawaiian coral reef. Because no company is currently active in this field, we do not consider this value for the Hawaiian context.

The research value is determined in a rather straightforward manner. All research budgets that are assigned to coral reef ecosystems in Hawai' $i$ are included in this value category. To this end, a brief survey was performed in Hawaic $i$ to determine the annual budget for reef-related research in 2001.
Nonuse values are based on the fact that people are willing to pay some amount of money for a good or service they currently do not use or consume directly. In the case of the Hawaiian coral reefs they are currently not visitors, yet they derive some benefit from the knowledge that the reef exists in a certain state and are willing to pay a certain amount of money to ensure that actions are taken to keep the reef in that state. The nonuse data applied here are discussed in this issue by Cesar and Van Beukering (2004).

\section{Case Studies}

Two case studies were selected within the region of the main Hawaiian Islands. Criteria that were used for the selection are both practical and more economic. Practical criteria include the location (i.e., even distribution among the Islands), the reef type (i.e., variation of ecosystems), type of threats (i.e., variation of threats addressed [see individual case 
studies]), data availability (i.e., how to access the data), and representativeness (i.e., can the case studies be used for extrapolation Hawai'i-wide). Economic criteria refer to whether the case studies address a range of benefits such as snorkeling, diving, fisheries, coastal protection, and biodiversity. The selected case studies were at Hanauma Bay (O'ahu), addressing tourist overuse, and the Kîhei coast (Maui), addressing excessive nutrients and algae blooms.

TOURIST OVERUSE AT HANAUMA BAY, $\mathrm{O}^{6} \mathrm{AHU}$. Hanauma Bay is the remnant of the inside of a large volcano, whose crater partly collapsed into the sea. The bay is located southeast of Waikikī on O'ahu and is one of the most heavily used marine reserves in the world. The Hanauma Bay Marine Life Conservation District (MLCD), established in 1976, was the first MLCD in Hawai'i. Reef monitoring showed an average coral cover of $25.8 \%$ at $3-\mathrm{m}$ depth and $27.0 \%$ at $10-\mathrm{m}$ depth. Macroalgae coverage was very low, at around $2 \%$, and percentages of crustose coralline algae and turf algae were high. Fishes were abundant, with densities of 417 fishes per $125 \mathrm{~m}^{2}$ at $3 \mathrm{~m}$ and 630 fishes per $125 \mathrm{~m}^{2}$ at $10 \mathrm{~m}$.

In the late 1980s, Hanauma Bay was being almost "visited to death," with 13,000 visitors a day at peak times. These crowds stirred up sediment, disturbed and trampled the coral and algae, dropped trash, fed the fishes, and left a slick of suntan lotion on the bay's surface. To decrease these impacts, the number of visitors was reduced by limiting the entry of cars to the parking lot. Also, a Hanauma Bay Educational Program (HBEP) was set up to improve the marine awareness of visitors. A $\$ 3$ admission fee is charged to non-Hawai' $i$ residents over the age of 13 , as well as a $\$ 1$ parking charge per car. These fees, together with shop concessions, give Hanauma Bay a solid financial base.

ALGAE BLOOMS ON THE KĪHEI COAST, MAUI. Algae blooms have been a recurring problem on reef flats off the southern and western coasts of Maui for many years. This has caused substantial, but localized, disturbance to the beach front, in terms of both its unattractive appearance and unpleasant odor.
Potential contributing factors include wastewater discharge, leaching of injection wells, storm water and agricultural runoff, and golf course runoff. This leads to nutrient enrichment of the shallow reef area, which can cause phytoplankton blooms. These blooms limit the amount of sunlight reaching stony corals, thereby affecting their health. The major algal blooms occur in the North Kinei area, which has an algae cover of over $50 \%$. Algae cover in South Kỉhei, which has not had such problems, is estimated at around $5 \%$. The North Kinhei algae problem is both a costly nuisance and a direct biological threat to local coral resources.

\section{RESULTS}

The results of the two case studies have two dimensions. On the one hand, the case studies involved elaborated field surveys aimed at revealing a particular economic aspect (i.e., tourist value, amenity value) of the coral reef at that site. This survey generated a snapshot of a particular value at a particular time (see Field Survey under each case study). Next, the possible changes of these values over time were simulated with the SCREEM model. The results of this exercise are presented in Scenario Analysis under each case study.

\section{Hanuama Bay}

FIELD SURVEY. Little is known about the behavior and perception of divers and snorkelers in Hawai'i. Tabata and Reynolds (1995) reported on the diving industry in 1990 from a macro perspective. The profile of divers and snorkelers in Hawai'i has never been systematically studied. To fill this gap, a survey was conducted in late 2001 and early 2002. Cesar et al. (2002) provided a full overview of the survey. The main purpose of the survey was to determine the average profile of each user group in terms of actual expenditure directly attributable to the diving or snorkeling trip, the consumer surplus for this experience, and the willingness to pay for a healthier marine environment. 


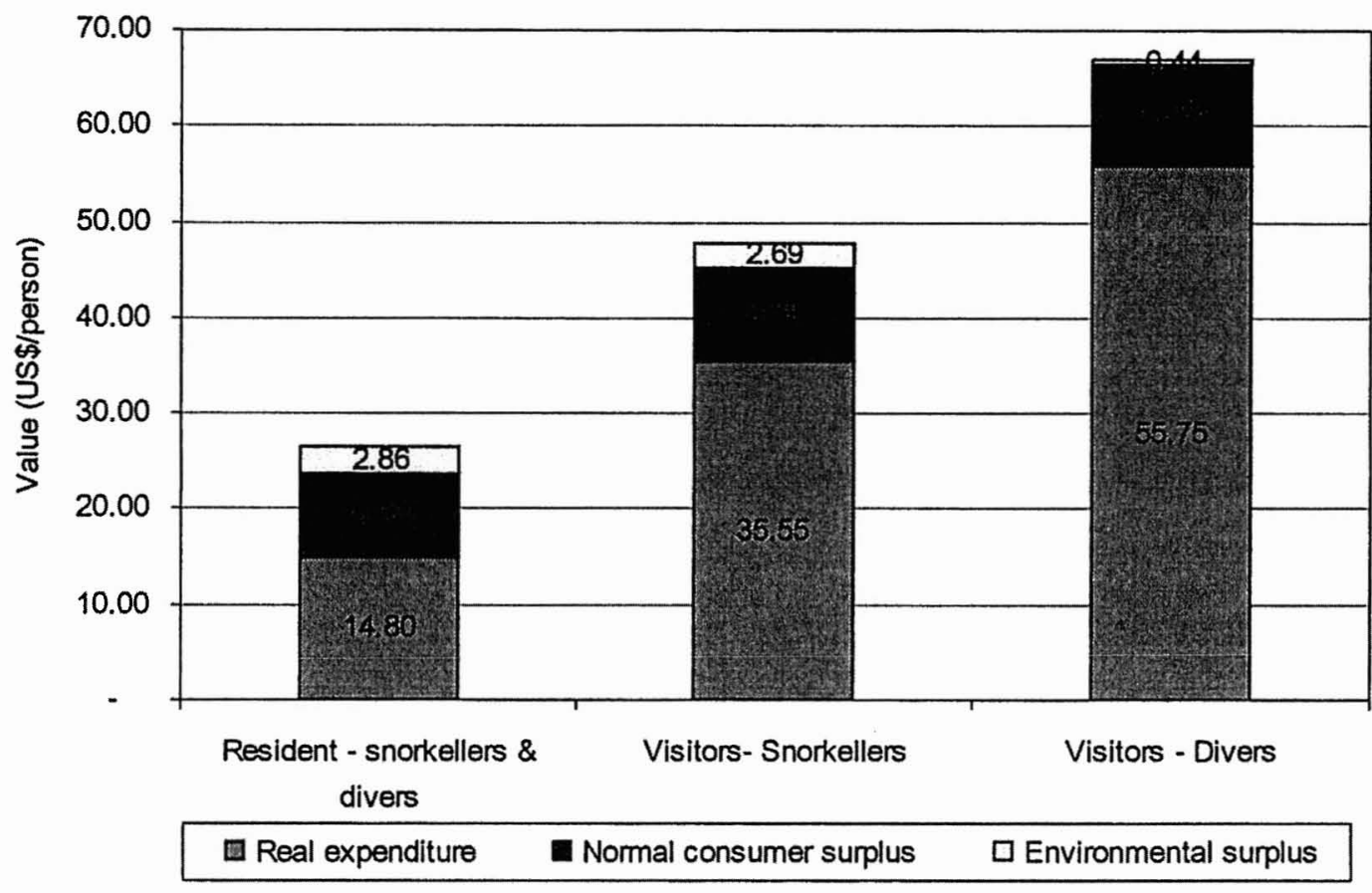

FIGURE 7. Allocation of real expenditures, consumer surplus for the same experience, and the surplus payment for a better marine environment.

The sample population was the active user group of coral reefs in Hawai'i. In total 50 divers and 260 snorkelers were interviewed. In addition, 150 nonusers were surveyed using a short version of the interview to investigate differences in perception between users and nonusers. At Hanauma Bay 152 interviews were conducted. Of these, 97 surveys were self-administered (i.e., respondents were handed surveys that they filled out and returned to the interviewer). Further details on the content of the survey are provided in this issue by Cesar and van Beukering (2004).

The results of this evaluation are shown in Figure 7. The real expenditures provide a predictable pattern. Residents generally spend much less on their dive or snorkel because they often have their own gear and also have less transportation costs to access the site. The consumer surplus for the same experience, without any environmental changes, is also largely as expected. Figure 7 shows that these are proportional to the real expenditures of the different user groups.

To determine the environmental component of the willingness to pay question, the consumer surplus was subtracted from the willingness to pay value obtained for a healthier marine environment. The surprising result is that the environmental component is much larger for the snorkeler $(\$ 2.69$ per snorkeling trip) than for the diver ( $\$ 0.44$ per dive). One would expect the more advanced diver to have a higher willingness to pay to protect the marine environment than the snorkeler. An explanation for this surprising result is that divers already have high costs and may therefore be less willing to increase their expenditures solely for the sake of marine conservation. Another explanation is that divers, who are generally more acquainted with marine protection than snorkelers, are more skeptical about the effectiveness of marine conservation programs. Residents have a 
relatively high willingness to pay for marine conservation (\$2.86), most likely because they feel more affiliated with their own reefs than the visitors do.

Next, the interviewer asked the respondents whether it is reasonable to insist that scuba divers and snorkelers pay a fee for marine preservation. Only $22 \%$ of the respondents felt that it was not the responsibility of the users of the coral reef to keep it in proper shape. They felt it was a responsibility of the state to do this. The majority of the respondents, however, felt that divers and snorkelers should also, in one way or another, be held responsible for the costs of marine conservation, thereby supporting the polluter pays principle. Typically, from the response of the subgroups, divers are more reluctant to take responsibility than snorkelers. One of the reasons for this reluctance is that they perhaps feel that their contribution to the overall problem of reef degradation is limited.

In summary, the survey shows that the users of corals reefs in Hawai' $i$, and Hanauma Bay in particular, are willing to pay much more for their diving or snorkeling experience than they are currently doing. The argument that implementing a user fee or increasing a user fee by a limited amount (e.g., $\$ 1$ or $\$ 2$ per experience) would discourage the user from pursuing their activities therefore seems unjustified. In fact, many users feel that it is reasonable to ask for a contribution from the users because they are also partly responsible for the damage done to the reef. The admission fee to Hanauma Bay could therefore be even as high as $\$ 10$ without having a notable impact on visitor numbers. However, from the viewpoint of equity such a high entry fee may be less desirable.

SCENARIO ANALYSis. The main goal of the Hanauma Bay case study was to determine the value of the reef at Hanauma Bay and to evaluate the effectiveness of the investment in the education center there in terms of costs and benefits. To answer these questions, the SCREEM model was applied. When determining the value of coral reefs at Hanauma Bay, the main question is what future conditions to take into account. The economic value with a specific intervention, such as the implementation of a compulsory education program, is most likely to be very different than the value without an intervention. Therefore we analyzed two distinct scenarios:

(1) With education: The visitors to $\mathrm{Ha}-$ nauma Bay pay their entry fee, pass the education stands, and watch a compulsory short film that describes the coral reefs in Hawai' $i$ and explains how visitors can help to minimize their impacts on the reefs. It is anticipated that physical damage and fish feeding will be considerably less in this scenario.

(2) Without education: The visitors to Hanauma Bay pay their entry fee but bypass the education stands and are not exposed to the film about coral reefs. Physical damage to the reef caused by standing on the reef and fish feeding will continue to occur.

The main economic effects in the $\mathrm{Ha}$ nauma Bay case study are (1) an increase in satisfaction of visitors to the bay, (2) the positive fishery spillover effect, (3) an increase in biodiversity value derived from a healthier coral reef, and (4) the so-called education spillover effect. This education spillover effect refers to the fact that the snorkelers and divers of Hanauma Bay go snorkeling on average at two or three other locations in Hawai' $i$ and therefore also behave better in those other reef areas. Education thus not only benefits Hanauma Bay itself but also prevents physical damage to other reefs. The education therefore can be considered a longlasting investment in environmental awareness and tourist behavior. Most critics of the education center generally ignore this effect and tend to look only at the effects that education has in Hanauma Bay itself.

In calculating the educational spillover effect, a distinction is made between residents and visitors. As far as visitors are concerned, active visitors snorkel on average 3.8 times during their stay in Hawai'i, of which one snorkel trip will be in Hanauma Bay. The education spillover effect for active visitors is therefore assumed to materialize in approximately two snorkeling trips outside Hanauma Bay. Accounting for this spillover effect we adopted the calculations reported in Cesar et al. (2002) on threats to the reefs of a damage 
TABLE 1

Recreational Benefits of the Different Users of Hanauma Bay (in \$)

\begin{tabular}{|c|c|c|c|c|c|}
\hline $\begin{array}{l}\text { Type of } \\
\text { Visitors }\end{array}$ & $\begin{array}{l}\text { Aggregate } \\
\text { Consumer } \\
\text { Surplus }\end{array}$ & $\begin{array}{c}\text { Direct } \\
\text { Expenditure } \\
\text { Attributed to } \\
\text { Hanauma Visit }\end{array}$ & $\begin{array}{c}\text { Indirect } \\
\text { Expenditure } \\
\text { Attributed to } \\
\text { Hanauma Visit }\end{array}$ & $\begin{array}{l}\text { Multiplier } \\
\text { Effect }\end{array}$ & $\begin{array}{c}\text { Total } \\
\text { Recreational } \\
\text { Value }\end{array}$ \\
\hline Residents & $1,097,550$ & 708,750 & - & 177,188 & $1,983,488$ \\
\hline U.S. West & $1,542,952$ & $1,891,360$ & $3,263,496$ & $1,288,714$ & $7,986,521$ \\
\hline U.S. East & $1,322,652$ & $1,621,315$ & $3,565,484$ & $1,296,700$ & $7,806,151$ \\
\hline Japan & $1,202,725$ & $1,474,309$ & $2,459,600$ & 983,477 & $6,120,111$ \\
\hline Canada & 236,093 & 289,404 & 707,163 & 249,142 & $1,481,802$ \\
\hline Europe & 225,881 & 276,886 & 582,582 & 214,867 & $1,300,217$ \\
\hline Other & 764,030 & 936,553 & $1,926,471$ & 715,756 & $4,342,810$ \\
\hline Total & $6,391,883$ & $7,198,577$ & $12,504,796$ & $4,925,843$ & $31,021,099$ \\
\hline
\end{tabular}

rate of $2 \mathrm{~cm}^{2}$ per trip. In the case of residents, it should be realized that active residents, who indicated snorkeling on average 10 times a year, will continue doing so for many future years. In other words, the accumulative effect of their education is much larger than for visitors. Calculations show that improved behavior of snorkelers results in less reef change (4 ha) than would otherwise take place. For divers, a damage reduction of approximately 0.2 ha is estimated.

Besides "educational spillovers" other forms of positive leakage may occur from Hanauma Bay. Some experts consider the bay as a "sacrificial site" within the overall system of Marine Protected Areas in Hawai'i. They believe that the degradation is acknowledged as being beyond the "optimal level" on a single site basis but that the resultant revenues are then adequate to fund the entire island's park system and provide protection in pristine areas where such protection might not otherwise be possible. This sort of "system" approach is becoming more common in network planning of Marine Protected Areas (see Morris 2002). We have ignored such spillover effects outside Hanauma Bay.

The findings of the survey were used in the analysis to calculate the recreational benefits of Hanauma Bay. The first step in this procedure was to identify the true user group of the coral reef of Hanauma Bay. After all, not all visitors actually go snorkeling or diving and are therefore not necessarily bene- fiting from the reef as such. The survey revealed that the most active users were Europeans, of whom $95 \%$ went snorkeling or diving. The least-active user groups were the Japanese, of whom only $60 \%$ actually put their head under water. The total number of users is estimated to be over 800,000 people.

Next, calculations were made of how much value can be attributed to this marine activity. We took into account four categories. First, we measured the welfare gain of the visitors by determining the consumer surplus. Second, we included the actual expenditure directly related to a snorkeling or diving experience. Third, we considered a share of the expenditure indirectly related to the marine experience, such as hotel costs and travel costs. Fourth, we adopted the multiplier effect developed by the Department of Business, Economic Development, and Tourism (2002) of 1.25 for the overall economy. These different categories are reported in Table 1.

Figure 8 shows the aggregated benefits consisting of the recreational values, the education spillover effects, the biodiversity values, and the fisheries spillover effect. Due to the further degradation of Hanauma Bay, if no proper education program is established, the value of Hanauma Bay will decrease slightly to $\$ 35$ million in 2050 . This decline is caused mainly by the reduction of the consumer satisfaction of the visitors. In the "with education" scenario, the value of Hanauma Bay can increase substantially, mainly due to 


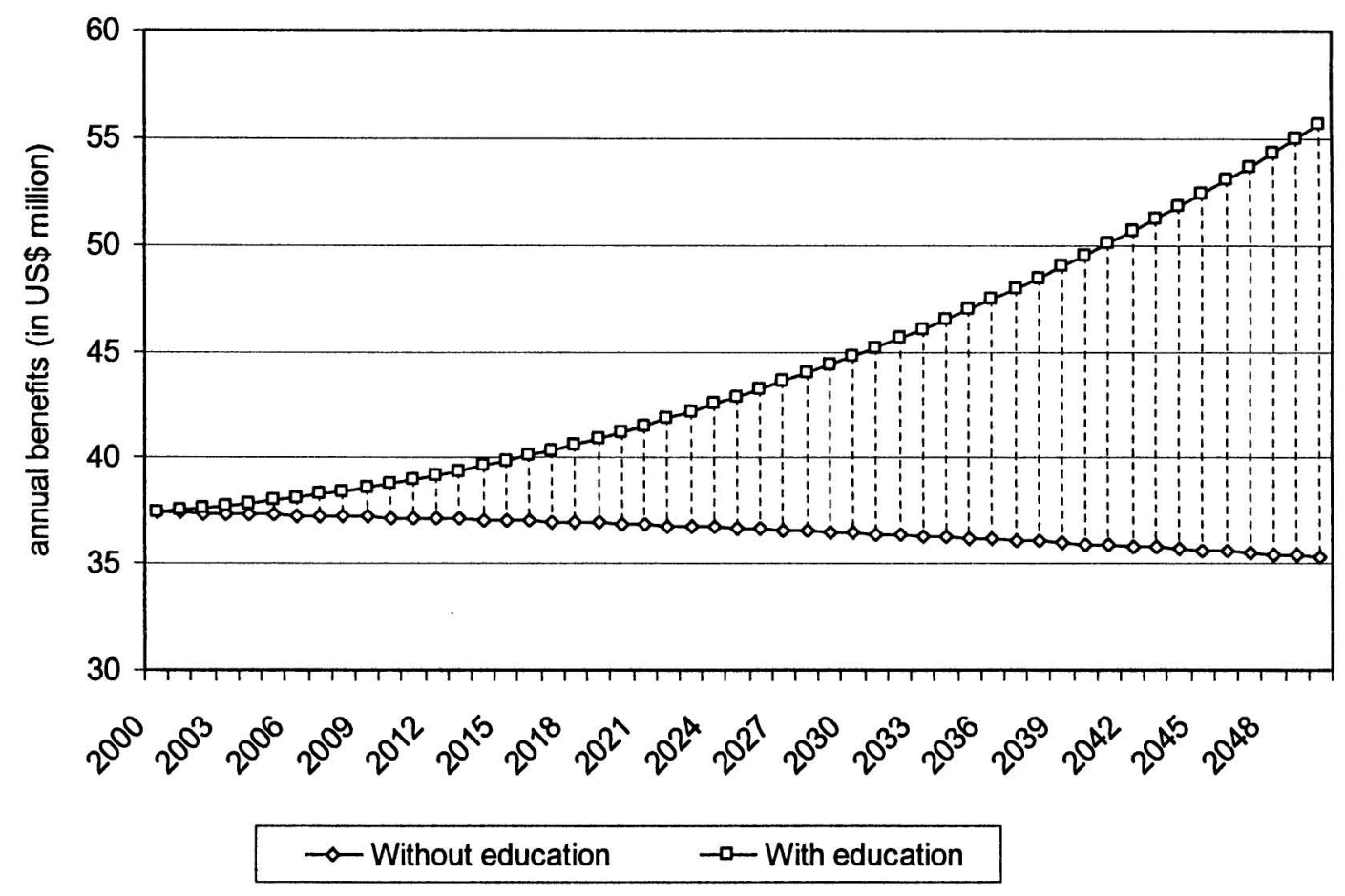

FIGURE 8. Annual benefits "with" and "without" education at Hanauma Bay.

its educational role for general coral reef use in Hawai' $i$. The area between the "with education" and "without education" scenarios represents the cost of inaction. At a discount rate of $4 \%$ this area representing the net benefits of education is valued at $\$ 100$ million. The composition of this amount is determined by the increased satisfaction of visitors to the bay (33\%), an increased biodiversity value derived from a healthier coral reef $(4 \%)$, and the education spillover effect (63\%).

The additional costs of the education program aggregate over time to $\$ 29$ million at a discount rate of $4 \%$. This is far less than the $\$ 100$ million net benefits just mentioned generated by the education program. In other words, because the benefit cost ratio at a $4 \%$ discount rate of 3.5 greatly exceeds 1 , the investment in the education program can be considered economically feasible. Only at a discount rate of more than $12 \%$ does the benefit cost ratio become less than 1 . Under those conditions, the project is no longer economically feasible. It should be realized, however, that besides economic motives there may exist other reasons, such as purely ecological or social ones, to pursue the education program.

The composition of the net benefits is as follows (Figure 9): value of increased satisfaction of visitors to the bay (33\%), an increased biodiversity value derived from a healthier coral reef $(4 \%)$, and the so-called "education spillover effect" (63\%). The latter comes from reduced coral trampling elsewhere by residents and tourists after watching the obligatory Hanauma video.

\section{Kīhei Coast}

FIELD SURVey. The Kīhei coast survey addressed two issues. First, an assessment was made of the damage costs for various stake- 


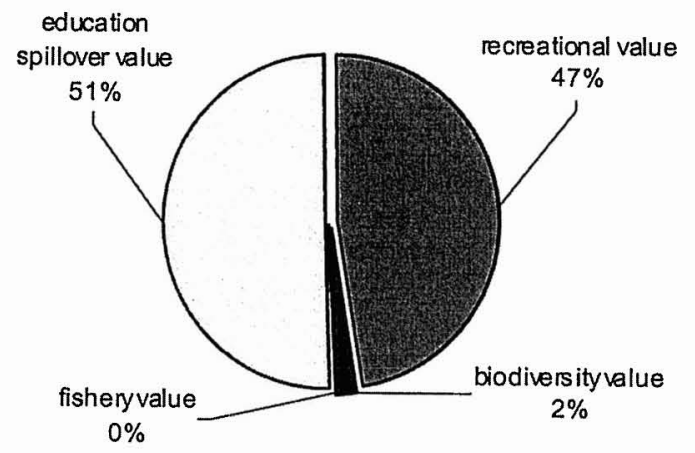

Figure 9. Allocation of benefits of an education program at Hanauma Bay.

holders related to the algae problem. Second, the potential remediation costs of the algae problem were examined.

The macroalgae problem on the Kinei coast has a negative impact on property values of the affected condominiums as well as the rental prices and vacancy rates in transient accommodations. To study this impact a survey was conducted in early 2002 that compared economic parameters of the oceanfront condominiums in North Kìhei that are affected by chronic algae problems with the experience of comparable, but unaffected, condominium complexes in South Kīhei. This comparison is difficult for several reasons. First, although the North Kinhei algae impact area is readily identified, not all condominium complexes within that area are affected equally throughout the year. Moreover, fluctuations per year are higher than those assumed in the model. In short, we measured the relatively long-term economic effects of the algae problem in North Kinhei. In particular, we concentrated on the difference in room rates, occupancy rates, and property values.

Room rates: As part of the survey, data were collected on daily (transient) room rates at 15 relatively large condominium properties that contained 745 units. Tax information was obtained only from ocean-front condominiums because these properties are most likely to be affected by the algae problem. Although data were collected on a variety of accommodations (e.g., studio, one bedroom, two bedroom, three bedroom, etc.), not all properties offered all options. To simplify the analysis, a one-bedroom unit was used as the basis for comparison. The room rate used was the lowest published ("rack") rate in effect on 1 May 2002.

The room rate comparison clearly suggests a substantial difference in the room rates of condominiums in the "algae zone" of North Kinhei from similar-sized condominiums in the southern "nonalgae" zone. This differential is most evident in the comparison of two nearly identical "sister" properties: the Menehune Shores and the Royal Mauian. These complexes are architecturally identical, and units in each project have the same floor space and layout. The one-bedroom units in the algae-zone Menehune Shores rent for slightly less that two-thirds the rates commanded by identical units in the Royal Mauian.

Occupancy rate: It is difficult to develop quantitative data on the occupancy rates of condominiums because condominium owners (or their guests) are constantly taking up or leaving residence in their own units. Thus, the rental pool is constantly changing. Furthermore, unlike hotels, the marketing of condominium rentals relies less on organized advertising or sales networks and more on word of mouth and return business or information channels such as guidebooks or internet sites. The situation is further complicated, because unit owners in a given complex may elect to self-rent their apartments as an alternative to having their units managed by a local rental management company. For example, one of the largest condominium complexes in the algae zone is the Maui Sunset. The property has over 216 units and rental marketing is handled by six agencies. In addition, numerous units are directly rented by owners.

Rental agents and owners who were interviewed from the "algae zone" properties were unanimous in the belief that they suffered lower occupancy rates due to the algae nuisance. It is interesting that there seemed to be a common belief that vacancy rates were between 5 and $10 \%$ lower in the algae area 
TABLE 2

Comparison of Sale Prices of One-Bedroom Units in the Menehune Shores and the Royal Mauian Condominium Complexes for 1998-2000

\begin{tabular}{|c|c|c|c|c|c|}
\hline \multirow[b]{2}{*}{ Year } & \multicolumn{2}{|c|}{ Menehune Shores } & \multicolumn{2}{|c|}{ Royal Mauian } & \multirow{2}{*}{$\begin{array}{l}\% \text { Difference } \\
\text { in Sales Price }\end{array}$} \\
\hline & No. of Sales & Average Price & No. of Sales & Average Price & \\
\hline 1998 & 6 & 156 & 3 & 440 & 182 \\
\hline 1999 & 21 & 194 & 3 & 382 & 97 \\
\hline 2000 & 12 & 222 & 8 & 495 & 123 \\
\hline Average 1998-2000 & 194 & 190 & & 439 & 131 \\
\hline
\end{tabular}

Source: Hawai'i state tax records.

than in similar properties in South Kinei. Although such estimates are subjective and anecdotal, they do reflect the professional opinion of rental agents who manage units both inside and outside the algae problem area.

Private property values: The market value of a real estate unit comprises many tangible and intangible factors related both to the condition of the unit and to its location. The algae problem is a real factor in the price of condominium units in the North Kinhei area. Everyone seems to accept that the algae problem makes North Kinhei condominiums less attractive and less valuable. There are two interrelated aspects to this property value impact. First, the algae nuisance makes units less attractive as residences. Second, the algae nuisance lowers property values by reducing the income-producing capacity of the units as rentals (i.e., lower rental rates + lower occupancy).

Due to resource constraints, estimates in this survey were based on a simplified statistical analysis only and not on the hedonic pricing method. To develop an estimate of the impact of algae on property prices, tax records for 771 units in North and South Kinei were analyzed for the period 19982000.

This comparison clearly shows a substantial difference. Though we were not able to prove this statistically, it is assumed that this can be attributed at least partly to North Kihei's algae problem. However, there are so many variables potentially affecting prop- erty values that the estimates probably need some refinement. To eliminate differences in property values that might be associated with basic design, as well as apartment and complex amenities, we compared sales prices for the sister properties Menehune Shores and Royal Mauian. These properties are, in terms of architecture, design, and amenities, largely identical. The details of this comparison are presented in Table 2.

From this comparison of nearly identical properties, it is clear that one-bedroom units in the algae zone (e.g., the Menehune Shores) were, over the 3-yr study period, only about $43 \%$ as valuable as one-bedroom units at the Royal Mauian. Clearly, the location of the two complexes had a very substantial influence on the value of the units. If we assume that the average price difference seen in the Royal Mauian-Menehune Shores comparison is representative of property differentials between the algae and nonalgae areas, then condominium owners in the algae area are experiencing a substantial depreciation of the value of their properties. Though we were not able to prove this statistically due to data constraints, interviews with condominium owners and managers clearly indicated that the algae problem was the single most important determinant of the price differential.

The major condominium properties in the algae zone have undertaken a privately funded beach cleanup program for a number of years. This program involves periodic (daily during peak seasons) collection of algae using traditional construction equipment. 
The collected algae is either bulldozed into shore berms along the beachfront or stacked into piles in front of the Maui Sunset complex. The stacked algae is collected by Maui County trucks as the need arises and hauled to local composting sites for recycling. The algae cleanup and removal operation is mildly controversial because the removal of beach sand is an inevitable part of the current process. The Maui County Public Works Department is in the process of buying a beach cleanup machine that will minimize sand removal and algae handling. The beach cleanup operation is undertaken by a private contractor at an annual cost to the condominiums of $\$ 55,000$.

SCENARIO ANALYSis. As mentioned, the main goals of the Kihei coast case study were to determine the value of the reef on the Kinei coast, and to evaluate the effectiveness of interventions that aim to reduce the nutrient outflow in the Kihei coastal waters in terms of net benefits. For this purpose the SCREEM model was applied. We analyzed economic values in this assessment under two distinct scenarios:

(1) With nutrient reduction: Several measures will be taken that are aimed to reduce the nutrient outflow into Kîhei waters. These include the upgrading of the Kihei sewage plant from secondary to tertiary treatment, and improved fertilizing practices in both the agricultural sector and the golf courses. Because current knowledge in this field is still insufficient we need to make a number of assumptions with regard to the effectiveness of these measures. This is explained later in this section.

(2) Without nutrient reduction: No nutrient reducing measures will be taken. This implies that the current trends of algae blooms will continue to occur, leading to further coral reef destruction and continued algae nuisance at Kìhei beaches.

The coral reefs at Kihei serve various purposes. Figure 10 shows the composition of the main benefits. The most important economic benefits of the coral reefs on the Kinei coast are the recreational and amenity values. The recreational benefits consist mainly of snorkelers that independently visit the reefs

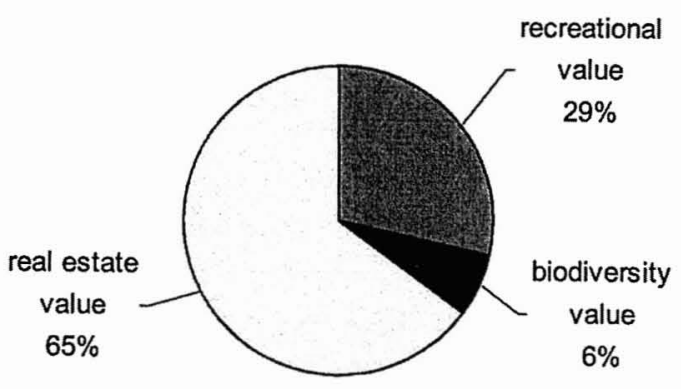

FIGURE 10. Allocation of main benefits if nutrient reductions are achieved.

offshore (29\%). The majority of the economic benefits of the coral reefs consist of amenity benefits derived from the differences in property values of houses, hotels, and condominiums at healthy and unhealthy coral reefs $(65 \%)$.

Figure 11 depicts development of the annual benefits derived from the coral reefs for the scenarios with and without nutrient reduction. It is not surprising that the annual benefits will further decline from \$25 million to $\$ 9$ million in a situation where the coral reefs will gradually disappear and where algae blooms will continue to occur. In a situation where nutrients are successfully reduced, however, the annual benefits will eventually increase by almost $\$ 30$ million. The majority of this increase is attributed to the growth in property values. In other words, if appropriate measures are taken, it will take approximately $50 \mathrm{yr}$ before the damage caused so far by the algae blooms on the Kinhei coast is completely eliminated. Due to the delay between the time of the interventions (e.g., sewage upgrade, fertilizer improvement) and the actual reduction of the nutrient levels in Kîhei waters, the annual benefits will inevitably decline for another 10 to $15 \mathrm{yr}$ before the reef will recover and the ecological effect will have materialized in economic benefits.

To get an idea of how the benefits of "action" (e.g., the shaded area between the two curves in Figure 11) compare with the cost of the required intervention, the cost of upgrading the sewage plant at Kinei from secondary to tertiary treatment has been esti- 


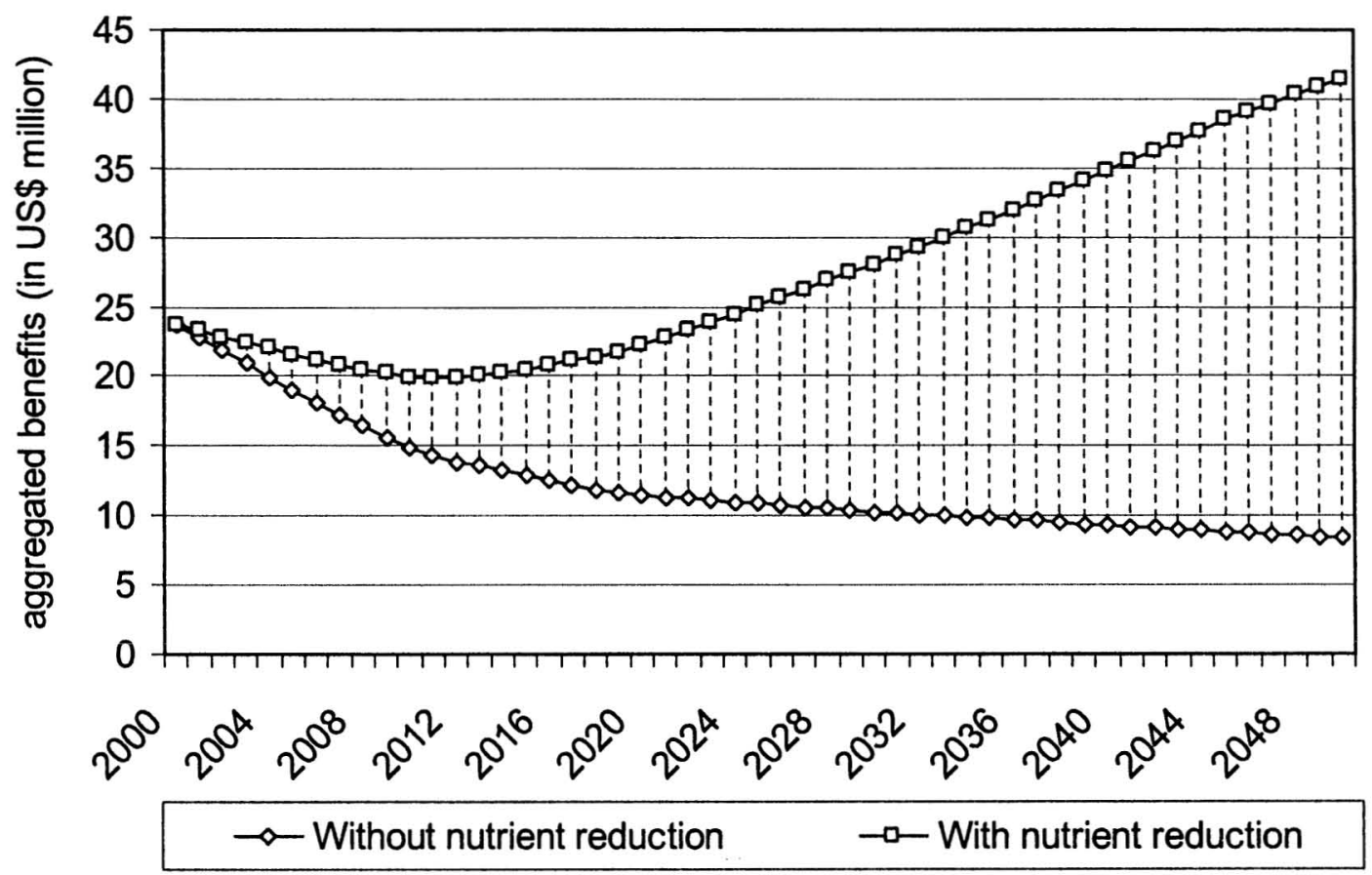

Figure 11. Development of benefits from the coral reefs with and without the reduction of nutrient levels on the Kihei coast.

mated. We do not claim that this would include all the costs required to solve the algae problem at Kinhei, but it gives us at least some rough idea of the comparison between benefits and costs.

Beginning in 1995, Maui County started a long-term upgrading program for its sewagetreatment plants at Lahaina and Kinhei. The plan was designed to upgrade treatment from secondary to tertiary levels and explicitly recognized the nutrient and algae problem. As part of this plan the county commissioned the Brown and Caldwell consulting company to study rate and fee alternatives for reclaimed water service. The study examined the costs of upgrading sewage effluents to levels that would be suitable for selling reclaimed water to a number of identified users. The study estimated the annual costs of the upgrading scheme to be slightly over $\$ 2.3$ million per year.
A sensitivity analysis was conducted for the relationship between the total economic value and the discount rate. For all discount rates tested, the benefit cost ratio exceeds 1 , implying the cost-effectiveness of the intervention. Two remarks are made concerning this conclusion. First, as mentioned, sewage treatment upgrading is only part of the problem and may therefore not be sufficient to solve the algae problem. The costs will therefore most likely be higher than assumed in this analysis. Second, the benefits taken into account are only those that relate directly to coral reefs. In reality, a number of site benefits will be achieved, such as health effects and water savings, that have not been taken into account in this study and that are often the sole reason to upgrade sewage systems. The benefits considered are therefore an underestimation of the real societal benefits that will occur. 


\section{DIsCUSSION}

The mutual relationship between ecological and economic processes of coral reef ecosystems is strong. Therefore, a multidisciplinary approach is essential in tackling the multiple threats that currently face the fragile coral reefs of Hawai'i. SCREEM is a first attempt to provide a platform for marine biologists and environmental economists to exchange knowledge on the degradation and management of the coral reefs of Hawai'i. Some would like to see more complex interrelationships in the model. Indeed, we acknowledge that the model is rather straightforward. Yet it provides a representation of the current state of the scientific knowledge available in the literature, even though the model simulations are far from accurate and sometimes lack the desired level of comprehension. Moreover, unlike most monodisciplinary studies, SCREEM contains the main elements required to oversee the full picture of coral reef management and thereby enables scientists and managers to evaluate ecological and economic impacts effectively.

Several conclusions can be drawn from the study at Hanauma Bay: (1) visitors to $\mathrm{Ha}$ nauma Bay are willing to pay much more for their experience $(\$ 10)$ than they are currently doing. This consumer surplus is even larger if they know this payment is used for conservation (\$12.50); (2) divers are less willing to contribute to conservation than snorkelers, (perhaps) because of their high expenditures or their skepticism about its effectiveness; (3) the education spillover effect dominates the economic value of the bay; and (4) the net benefits of the education program ( $\$ 100$ million) over time greatly exceed the cost of the program (\$23 million) over time.

The Kinhei coast study is incapable of revealing the full picture of the associated costs and benefits of the algae problem. To address these issues appropriately, more geological, hydrological, ecological, and economic information is required. This can only be achieved with the help of a multidisciplinary team and with more research funds. Despite these handicaps, an attempt was made to come up with a rough estimate of the eco- nomic values related to the coral reefs and the algae problems and to compare these with an estimate of the costs of upgrading the sewage plant in Kinhei. Several conclusions have been drawn: the losses of real estate value and hotel business are the main effects of the algae problem at Kinhei; and it seems that the costs of reducing nutrient concentrations are smaller than the loss of benefits in the algae problem.

The two case studies show the costs and benefits of coral reef management. Expressing the various elements in economic terms can help policy makers to better understand the trade-offs involved in coral reef management and the costs associated with a policy of "inaction," thereby providing arguments for the State of Hawai'i to reconsider its extremely low budget allocation for coastal zone management compared with other states.

\section{ACKNOWLEDGMENTS}

We thank Mike Hamnett, Kristine Davidson, and Risa Minato of the Hawai'i Coral Reef Initiative Research Program for their support. Funding from NOAA's Coastal Ocean Program for the study and from the Institute for Environmental Studies at the Vrije Universiteit in Amsterdam for the write-up of the paper is gratefully acknowledged. We also thank John Dixon for helping to set up the study and Sam Pintz for his Kinhei work. Constructive comments by Jack Ruitenbeek and Alan White have improved the paper considerably. The usual caveats apply.

\section{Literature Cited}

Barton, D. N. 1994. Economic factors and valuation of tropical coastal resources. Senter for Milijø-og Ressursstudier Report 14/94, Bergen, Norway.

Birkeland, C., ed. 1995. Life and death of coral reefs. Chapman-Hall Science, New York.

Cesar, H. S. J., and P. J. H. van Beukering. 2004. Economic valuation of the coral reefs of Hawai'i. Pac. Sci. 58:231-242.

Cesar, H. S. J., P. J. H. van Beukering, W. Pintz, and J. Dierking. 2002. Economic 
valuation of the coral reefs of Hawaici. Hawai'i Coral Reef Initiative, University of Hawai'i, Honolulu.

Clark, A. M., and D. A. Gulko. 1999. Hawai'i's state of the reefs report, 1998. State of Hawai' $i$, Department of Land and Natural Resources, Honolulu.

Costanza, R., R. d'Arge, R. de Groot, S. Farber, M. Grasso, B. Hannon, K. Limburg, S. Naeem, R. V. O'Neill, J. Paruelo, R. G. Raskin, and P. Sutton. 1997. The value of the world's ecosystem services and natural capital. Nature (Lond.) 387:253260.

Department of Business, Economic Development, and Tourism. 2002. The Hawai'i input-output study, 1997-Benchmark report. State of Hawai'i Research and Economic Analysis Division, Honolulu.

Friedlander, A. M., and J. D. Parrish. 1998. Habitat characteristics affecting fish assemblages on a Hawaiian coral reef. J. Exp. Mar. Biol. Ecol. 224:1-30.

Grigg, R. W., and S. J. Dollar. 1990. Natural and anthropogenic disturbance on coral reefs. Pages 439-452 in Z. Dubinsky, ed. Ecosystems of the world 25. Coral reefs. Elsevier, Amsterdam, The Netherlands.

Gulko, D. A., J. E. Maragos, A. M. Friedlander, C. L. Hunter, and R. E. Brainard. 2001. The status of coral reefs in the $\mathrm{Ha}$ waiian Archipelago. State of Hawai'i, Department of Land and Natural Resources, Honolulu.
Gustavson, K., R. Huber, and R. Ruitenbeek, eds. 2000. Integrated coastal zone management of coral reefs: Decision support modeling. The World Bank, Washington, D.C.

Moberg, F., and C. Folke. 1999. Ecological goods and services of coral reef ecosystems. Ecol. Econ. 29:215-233.

Morris, B. 2002. Transforming coral reef conservation in the 21st century: Achieving financially sustainable networks of Marine Protected Areas. Conservation International/The Nature Conservancy, Washington, D.C./Honolulu.

Pearce, D. W., and K. R. Turner. 1990. Economics of natural resources and the environment. Harvester Wheatsheaf, London.

Rogers, C. S. 1990. Responses of coral reefs and reef organisms to sedimentation. Mar. Ecol. Prog. Ser. 62:185-202.

Spurgeon, J. P. G. 1992. The economic valuation of coral reefs. Mar. Pollut. Bull. 24 (11): 529-536.

Tabata, R. S., and E. Reynolds. 1995. Hawai'i's recreational dive industry: $\mathrm{Re}$ sults and recommendations of a 1990 study in Hawai'i. Department of Business, Economic Development, and Tourism, State of Hawai'i, Honolulu.

VENSIM. 2000. The Ventana simulation environment. Vensim Professional 16, version 4.2a. Ventana Systems, Harvard University, Cambridge, Massachusetts. 